\title{
O Papel das Aceleradoras na Evolução das Startups
}

\section{The Role of Accelerators in the Evolution of Startups}

\author{
Fabrício Beltrami \\ Universidade do Vale do Rio dos Sinos - UNISINOS - Brasil \\ fabricio.beltrami@gmail.com \\ ORCID: 0000-0001-9023-6620 \\ Jorge Renato Verschoore \\ Universidade do Vale do Rio dos Sinos - UNISINOS - Brasil \\ jorgevf@unisinos.br \\ ORCID: 0000-0001-7588-7871
}

Submetido em 09/11/2020; Aprovado em 09/01/2021.

\begin{abstract}
Resumo
Objetivo: Este ensaio teórico analisa o papel das aceleradoras nos estágios evolutivos de uma startup e como a influência na estratégia do empreendedor, através de seus programas de aceleração, pode ser direcionada em maximizar a geração de valor para todos os participantes. Método: A abordagem foi desenvolvida por meio de uma revisão bibliográfica sobre Causation - Effectuation Theory, pesquisas sobre programas de aceleração e metodologias de inovação. Resultados: Os resultados sugerem que as aceleradoras têm papel importante no desenvolvimento do ecossistema de startups e no estímulo ao empreendedorismo, com destaque para os programas de aceleração que: (1) selecionam empreendedores orientados à tomada de decisão através da lógica efectual, (2) possuem redes de apoio com governança baseada em confiança e cooperação, e (3) mantém o foco empreendedor da startup ao final do programa de aceleração. Contribuições: 0 estudo contribui na discussão das dinâmicas temporais e de relacionamento entre aceleradoras e empreendedores pela Causation - Effectuation Theory, além de propor um framework para guiar gestores de aceleradoras e empreendedores à frente de startups.
\end{abstract}

Palavras-chave: Aceleradoras, Causation - Effectuation Theory, Empreendedorismo, Estratégia, Startups.

\section{Abstract}

Objective: This theoretical essay analyzes the role of accelerators in the evolutionary stages of a startup and how the impact on the entrepreneur's strategy, through their acceleration programs, can be directed towards maximizing the generation of value for all participants. Method: The approach was developed through a literature review on Causation - Effectuation Theory, research on acceleration programs and innovation methodologies. Results: The results suggest that the accelerators play an important role in the development of the startup ecosystem and in stimulating entrepreneurship, with emphasis on the acceleration programs that: (1) select entrepreneurs oriented to decision making through the effectuation logic, (2) have supportive networks with governance based on trust and cooperation, and (3) maintains the entrepreneurial focus of the startup at the end of the acceleration program. Contributions: The study contributes to the discussion of the temporal and relationship dynamics between accelerators and entrepreneurs under the Causation - Effectuation Theory, in addition to proposing a framework to guide accelerator managers and entrepreneurs ahead of startups. Keywords: Accelerators, Causation - Effectuation Theory, Entrepreneurship, Strategy, Startups.

\section{Introdução}

O termo "unicórnio", utilizado para definir startups com valor de mercado superior a 1 bilhão de dólares, foi cunhado, em 2013, pela investidora de risco, Aileen Lee, em artigo publicado na revista online Techcrunch (Lee, 2013). Naquele ano, 39 startups foram consideradas unicórnio. Oito anos depois, em 2021, a lista ampliou-se para 513 startups unicórnio, segundo acompanhamento feito pela 
empresa de pesquisa $C B$ Insights de Nova Iorque ${ }^{1}$. Inicialmente restrito aos Estados Unidos, este fenômeno encontrou na China um segundo protagonista, com 3 de cada 4 startups unicórnio sediadas nesses dois países, além de expandir e propagar-se para outros 31 países, incluindo o Brasil. Em valores de hoje, esse nicho de empresas iniciantes possui um valor agregado de mercado equivalente a 1,6 trilhão de dólares.

Embora a atividade empreendedora não seja novidade, três elementos se mostram inéditos: tecnologia, dinheiro e conhecimento. Tecnologias de ponta são acessíveis cada dia a custos menores e disponibilizadas ao público através de telefones inteligentes e conexões à internet onipresentes, possibilitando um acesso direto ao consumidor final com mínima ou nenhuma intermediação (Van Alstyne, Parker \& Choudary, 2016). Investidores de risco interessados em oportunidades de maior retorno têm usado seus recursos para financiar ideias com potencial de crescimento exponencial: as empresas com maior capacidade absortiva, competentes na tarefa de obter e transformar novas informações em oportunidades comerciais, ganham atratividade (Jeong, Kim, Son \& Nam, 2020). Farta literatura está disponível em linguagem simples sobre inúmeras metodologias direcionadas para a geração, validação, prototipação e execução de ideias e modelos de negócio inovadores, como Design Thinking (Brown, 2008), Business Model Generation (Osterwalder \& Pigneur, 2010) e Lean Startup (Ries, 2012).

Seja por interesse estratégico ou pressão da concorrência, empresas maduras buscam nas startups novos modelos de negócio ou vantagens competitivas que são difíceis ou arriscadas de desenvolver internamente (Weiblen \& Chesbrough, 2015). Tais empresas, ao se interessarem pelas startups, fornecem um estímulo adicional ao ecossistema e ao mercado. Esse cenário no qual o empreendedor com boas ideias acessa facilmente tecnologia, dinheiro e conhecimento, vislumbrando múltiplas chances de sucesso (seja pela conquista de uma fatia ou nicho de mercado), ou então crescendo por meio de parceria, fusão e aquisição por empresas consolidadas, motiva um número cada vez maior de pessoas que, por necessidade ou oportunidade, assumem os riscos e as incertezas de criar seu próprio negócio, inspirados pelo exemplo dos fundadores bem sucedidos dessas startups unicórnio e pelo notável crescimento desses empreendimentos em um curto espaço de tempo.

As incubadoras criadas nos ambientes de pesquisa ou por agências de fomento iniciaram o movimento de apoio ao empreendedor, fornecendo espaço físico e recursos básicos. Entretabto, a partir dos anos 2000, o conceito evoluiu para aceleradoras profissionais (Theodorakopoulos, Kakabadse \& McGowan, 2014). 0 principal objetivo de uma aceleradora profissional é suportar uma ideia de negócio no seu estágio inicial, ajudando o empreendedor a desenvolvê-la a patir de mentoria, buscando parcerias estratégicas e fornecendo aporte financeiro em troca de uma participação societária para que, após o programa de aceleração, ela obtenha retorno financeiro com a venda da sua participação para fundos de venture capital em uma nova rodada de investimentos. (Pauwels, Clarysse, Wright \& Van Hove, 2016). 0 foco deste ensaio se concentra nas aceleradoras profissionais que aportam seus próprios recursos materiais (capital) e imateriais (mentoria) para suportar empreendedores e startups em troca de uma participação para venda futura, apostando no desenvolvimento da ideia e na valorização do modelo de negócio. Incubadoras sem fins lucrativos ou institucionais, espaços de coworking restritos à colaboração informal, assim como aceleradoras corporativas orientadas à promoção do intraempreendedorismo dentro de empresas operam em uma lógica de negócios distinta e estão fora do escopo deste ensaio.

O avanço teórico para a compreensão do fenômeno empreendedor e, em especial, do indivíduo empreendedor tem, na teoria de Causation - Effectuation, pela pesquisa de Saras Sarasathy, um suporte relevante para o entendimento dos fatores que aumentam a probabilidade de sucesso. Mesmo que milhares de empreendedores não compartilhem a mesma sorte numa realidade que apresenta taxas de mortalidade elevadas, de 8 para cada 10 startups (Sarasvathy, 2001), uma série de esclarecimentos para a teoria de estratégia decorre desta pesquisa, ajudando na compreensão de: (1) quais são os elementos capazes de produzir empresas iniciantes com alto valor de mercado a partir de recursos escassos, superando empresas consolidadas; (2) como a estratégia de mercado relacionada ao posicionamento colaborativo ou competitivo com outras empresas e com o ecossistema direciona o acesso aos recursos necessários; e (3) qual pode ser o papel e a influência dos programas de aceleração nos estágios iniciais do desenvolvimento desses negócios, em especial nas estratégias de desenvolvimento, crescimento e geração de valor.

Empreender, no Brasil, vem se destacando como uma atividade de afirmação e ascensão social, 
moldando uma identidade profissional valorizada pela sociedade. No período recente, de 2002 a 2016 , as taxas de estabilidade e sobrevivência das empresas iniciantes aumentaram, com o empreendedorismo de oportunidade superando o de necessidade (Da Silva \& Silva, 2019). Por ser uma atividade associada a risco e incerteza, recai sobre o papel das aceleradoras profissionais um importante apoio para o sucesso do empreendedor e para o desenvolvimento do ecossistema de inovação.

0 interesse deste artigo está direcionado para a análise da dinâmica de relacionamento que se estabelece entre o empreendedor e a aceleradora, a partir da adesão a um programa de aceleração, observando as implicações estratégicas existentes em cada um dos estágios sequenciais de desenvolvimento da startup. A seção 2 aborda as motivações e a relação entre empreendedor e aceleradora; a seção 3 aborda o desenvolvimento do negócio em cada um dos seus estágios, encerrando com a proposição de um framework de análise do valor obtido pelo programa de aceleração, e considerações finais na seção 4 .

\section{Empreender e Acelerar}

Tornar-se um empreendedor, $C E O$, founder ou co-founder de uma startup de sucesso tem sido o desejo de carreira para muitos jovens e profissionais experientes que buscam ser donos do seu próprio negócio. Essa atitude é reforçada por um ativismo social cada vez mais comum, presente na intenção de mudar o mundo, deixar uma marca pessoal, um legado. Nesse contexto, surgem mais empreendedores com ideias em busca de ajuda e apoio, incentivando a criação de aceleradoras que possam suportá-los em seus desafios. A compreensão mais aprofundada sobre o que cabe a cada um desses papéis, seus objetivos e a dinâmica de relacionamento é necessária para que a inovação resultante possa entregar os melhores resultados.

\subsection{0 empreendedor}

Um empreendedor pode ser considerado "Alguém que cria um negócio diante de riscos e incertezas com o objetivo de obter lucro e crescimento, identificando oportunidades significativas e reunindo os recursos necessários para capitalizá-las" (Zimmerer, Scarborough \& Wilson, 2008). Dessa definição, pode-se inferir os desafios que o indivíduo empreendedor enfrenta.

Ao propor o modelo de Causation - Effectuation (Sarasvathy, 2001; 2009) como direcionador da tomada de decisão do empreendedor, evidenciando uma preferência à lógica causal (causation) em situações de risco com probabilidades conhecidas, e uma preferência à lógica efectual (effectuation) em situações de incerteza com resultados desconhecidos, Sarasvathy estabeleceu uma dualidade complementar que explica, em grande parte, o sucesso de empreendedores. Sarasvathy constatou que empreendimentos inovadores iniciados com poucos recursos, sem uma definição clara de objetivos, tendem a exigir do empreendedor uma abordagem mais efectual do que causal.

A tomada de decisão pela lógica do modelo effectuation simultaneamente se opõe e complementa a lógica do modelo causation como duas faces da mesma moeda. É importante evitar a consideração exclusiva de uma sobre a outra, sendo esperado que o mesmo empreendedor alterne episódios efectuais ou causais conforme o momento, motivado por fatores internos ou externos. Preferir uma ou outra abordagem não impede nem limita bons resultados, que em qualquer caso podem ser alcançados pelos dois caminhos (Jiang \& Rulling, 2019; Jiang \& Tornikoski, 2019).

\begin{tabular}{|l|l|l|}
\hline \multirow{2}{*}{ Lógica } & \multicolumn{1}{c|}{ Causation / Causal } & \multicolumn{1}{c|}{ Effectuation / Efectual } \\
\hline Critérios de decisão & $\begin{array}{l}\text { Dado o objetivo, estabelecer os meios para } \\
\text { atingi-lo. }\end{array}$ & Dados os meios, forjar os objetivos possíveis. \\
\hline Risco e Incerteza & $\begin{array}{l}\text { Surpresas são negativas, exigindo investi- } \\
\text { mento para serem evitadas ou neutraliza- } \\
\text { das. }\end{array}$ & $\begin{array}{l}\text { Surpresas podem ser positivas, devendo ser ala- } \\
\text { vancadas em oportunidades. }\end{array}$ \\
\hline Atitude & Prever os aspectos de um futuro incerto. & Controlar os aspectos de um futuro imprevisível. \\
\hline Competências & Que explorem conhecimento. & Que explorem contingências. \\
\hline Contexto & $\begin{array}{l}\text { Ambientes estáticos, lineares e independen- } \\
\text { tes. }\end{array}$ & Ambientes dinâmicos, não lineares e ecológicos. \\
\hline Resultados & $\begin{array}{l}\text { Fatia de mercado em mercados existentes } \\
\text { através de estratégias competitivas. }\end{array}$ & $\begin{array}{l}\text { Novos mercados criados através de alianças e } \\
\text { outras estratégicas cooperativas. }\end{array}$ \\
\hline
\end{tabular}

Quadro 1 - Comparativo Causation - Effectuation (Fonte: adaptado de Sarasvathy \& Dew, 2005)

A contribuição dos estudos de Sarasvathy integra e amplia o alcance de teorias anteriores sobre 
aspectos ambíguos da estratégia como exploitation - exploration (March, 1982; 1991), deliberate strategy - emergent strategy (Mintzberg, 1994) e enactment - retention - selection (Weick, 1979). Embora na inovação cercada por maior grau de incertezas haja uma tendência à lógica efectual sobre a causal, cabe ao empreendedor estar preparado para usar ambas, conforme mostrado no comparativo do quadro 1.

O empreendedor, para refinar e viabilizar sua ideia, em algum momento precisa compartilhar sua visão com participantes externos (Autio, Nambisan, Thomas \& Wright, 2018), evoluindo com especialistas e colaboradores para uma ideia tangível e viável. Esse estágio em que o empreendedor busca consolidar sua visão em um protótipo, definindo um possível modelo de negócio, tende a ser o ponto ideal de entrada para um programa de aceleração.

\subsection{A aceleradora}

Uma aceleradora existe para apoiar o empreendedor a partir do instante em que ele vislumbra uma oportunidade de mercado a ser explorada. Nas aceleradoras profissionais, esse apoio é fornecido por meio de um programa formal de aceleração, usualmente com duração definida e seguindo uma metodologia proprietária da aceleradora (Cohen \& Hochberg, 2014). A partir desse programa, são fornecidos recursos tangíveis (como investimento inicial e espaço físico para trabalho), além de recursos intangíveis (como mentoria e acesso a todo tipo de facilidades técnicas e serviços básicos administrativos que suportem a operação inicial). É comum que a aceleradora conte com um corpo de especialistas em vários assuntos demandados conforme a necessidade. Como garantia e contrapartida, o empreendedor concede um percentual de participação da sua empresa à aceleradora.

Não há um modelo padronizado para o funcionamento das aceleradoras, mas destacam-se cinco processos principais (Pauwels et al., 2016): (1) Programa de Aceleração, representando todos os serviços ofertados como mentoria e suporte; (2) Foco Estratégico, estabelecendo se há um ou mais nichos ou geografias de atuação; (3) Processo Seletivo, que define como a escolha das startups aceleradas é realizada; (4) Estrutura Financeira, definindo a origem e as regras para o financiamento das iniciativas; e (5) Alumni, mantendo um vínculo com as startups que já tenham finalizado o programa.

Algumas aceleradoras se especializam em segmentos específicos de negócios: agricultura (agrotechs), educação (edtechs), finanças (fintechs), jurídico (lawtech), logística (logtech), saúde (healthtech), seguros (insurtech), sustentabilidade (greentech), tecnologia (infotech), viagens (traveltech), e na medida em que as tecnologias evoluem, criam-se inúmeras classificações e opções diferentes de segmentos. A escolha de um nicho fortalece a capacidade de montar uma rede com maior conhecimento sobre o segmento escolhido, embora essa decisão também possa limitar as opções de inovação para a aceleradora ao concentrar seu risco em um único segmento.

O capital humano das aceleradoras é o responsável por executar seus objetivos estratégicos e, apoiado por bons processos de gestão orientados à performance, são um fator essencial para que elas possam se manter sustentáveis. Atingem sucesso na proporção direta da qualidade na seleção dos empreendedores aos quais se associam e na efetividade de suas mentorias em maximizar os resultados da startup acelerada, o que exige um cuidado especial com as pessoas que formam sua equipe, e que serão a sua imagem para o mercado (Vanderstraeten \& Matthyssens, 2012).

Ao final do programa de aceleração, espera-se que a startup esteja consolidada em um negócio com receita recorrente e perspectiva de evolução promissora no mercado como resultado de todos os esforços de qualificação e mentoria realizados. Em termos financeiros, é esperado que o investimento inicial realizado pela aceleradora possa ser recuperado com a venda da sua participação acionária para fundos de investimento em uma nova rodada de investimento promovida em Demo Days, que são apresentações curtas de todas as startups participantes do programa de aceleração para investidores qualificados, sendo comum que elas sejam agrupadas em turmas de aceleração, entrando e saindo juntas do programa. Essa prática dá foco e organiza a mentoria da aceleradora (Cohen \& Hochberg, 2014).

\subsection{Dinâmica do relacionamento}

É importante notar que há um processo seletivo de mão dupla entre o empreendedor e a aceleradora: ambos precisam concordar com os termos da outra parte para, então, formalizar a relação por meio de um contrato. É natural que os termos sejam negociados definindo condições do aporte financeiro, percentual de participação societária, duração e cronograma do programa, concessões e limites. Aceleradoras que investem no modelo de cota condominial possuem um grupo de cotistas, exigindo 
uma assembleia para tomada de decisão. Como há maior demanda de empreendedores do que aceleradoras disponíveis, há uma vantagem a favor das aceleradoras no processo de escolha que tende a ser competitivo para as startups. 0 empreendedor vincula-se a uma única aceleradora, enquanto a aceleradora provê suporte a uma turma de empreendedores em cada edição do seu programa de aceleração, sendo natural que, ao longo do processo, algumas startups ganhem maior atenção e prioridade do que outras (Pauwels et al., 2016). Essa é uma tensão interna permanente ao longo de todo o programa de aceleração.

Como evidenciado por March (1991) para a dualidade exploitation - exploration, ao afirmar que as duas lógicas precisam ser consideradas para se obter êxito no longo prazo, torna-se importante buscar um equilíbrio entre elas. Uma predominância de exploitation pode levar à armadilha do sucesso ao privilegiar apenas melhoria contínua e eficiência, assim como a predominância de exploration pode levar à armadilha do fracasso ao privilegiar a inovação, sem fortalecer a oferta existente (Gupta, Smith \& Shalley, 2006). São armadilhas quando uma das abordagens é considerada como a única alternativa, tirando o espaço da outra. Entre as dinâmicas de causation - effectuation também se percebe a necessidade de equilíbrio, mais difícil de obter quando os recursos são escassos ou quando a tecnologia ou mercado em questão são dinâmicos. Enquanto exploitation - exploration volta-se ao conhecimento e aprendizado, causation - effectuation volta-se à tomada de decisão e gestão de riscos (March, 1982; 1991; Sarasvathy, 2001; 2009). Espera-se que a aceleradora contribua com o empreendedor nesse equilíbrio, que é dinâmico e diferente a cada fase.

0 empreendedor, como estrategista e tomador de decisão, está interessado em desenvolver e consolidar seu modelo de negócio a longo prazo a partir da inovação e da conquista de mercado. A aceleradora, como uma consultoria especializada, está interessada em um retorno financeiro de curto prazo a partir da valorização exponencial do negócio. Essa diferença de expectativas - longo prazo versus curto prazo - pode confrontar o posicionamento do empreendedor (Sarasvathy, 2001; 2009) com o posicionamento da aceleradora (Cohen \& Hochberg, 2014), principalmente se usarem lógicas diferentes, causais ou efectuais.

Diferente de outras aceleradoras que contam com apoios institucionais, as aceleradoras profissionais são empresas de consultoria que precisam atingir taxas de sucesso superiores às taxas de insucesso. Aceleradoras e empreendedores têm em comum nas suas atividades o fato de serem dois agentes tomadores de risco. No entanto, como associados, empreendedor e aceleradora precisam alinhar objetivos e lidar com as tensões inerentes ao empenho de inovar, conforme apresentado no quadro 2.

\begin{tabular}{|l|l|l|}
\cline { 2 - 3 } \multicolumn{1}{c|}{$\begin{array}{l}\text { Contexto } \\
\text { Interno }\end{array}$} & $\begin{array}{l}\text { Empreendedor } \\
\text { no processo seletivo, na prioridade dos recursos } \\
\text { recebidos e, na rodada final, pelos investimentos. }\end{array}$ & $\begin{array}{l}\text { Aceleradora } \\
\text { equilibrar as demandas de recurso financeiro e } \\
\text { mentoria com foco na expectativa de desempenho. }\end{array}$ \\
\hline $\begin{array}{l}\text { Contexto } \\
\text { Externo }\end{array}$ & $\begin{array}{l}\text { Visão de longo prazo, objetivando levar seu modelo } \\
\text { de negócio para o mercado com competitividade e e } \\
\text { capaz de sobreviver frente à concorrência. }\end{array}$ & $\begin{array}{l}\text { Visão de curto prazo, objetivando maximizar o } \\
\text { retorno financeiro da consultoria aplicada no de- } \\
\text { senvolvimento da startup. }\end{array}$ \\
\hline
\end{tabular}

Quadro 2 - Objetivos e Tensões esperados entre Empreendedor e Aceleradora (Fonte: elaborado pelo autor)

Critérios objetivos para identificar e medir o grau da inclinação causal ou efectual podem fornecer construtos úteis para a comparação e identificação de pontos de tensão entre empreendedor e aceleradora. A partir desses construtos é possível utilizar uma escala de referência para medição do grau causal ou efectual de cada parte (Chandler, DeTienne, McKelvie \& Munford, 2011; McKelvie et al., 2019). Aplicando essa escala em campo nas diferentes fases do programa de aceleração, torna-se possível atingir um aprofundamento teórico para as proposições deste estudo, já antecipando uma oportunidade de pesquisa futura com base nesses achados.

\section{Fases empreendedoras}

É conveniente separarmos a evolução de uma empresa iniciante que se proponha a inovar em três processos sequenciais: standup, startup, scaleup (Autio et al., 2018). São, também, referidos de forma similar como dimensões: desk, pre-market, market (Elia, Margherita \& Passiante, 2020). Independente da nomenclatura, ambos os estudos se referem aos estágios de: (1) standup/desk: definição do conceito a ser explorado, elaboração do modelo de negócio, montagem do time de trabalho e prototipação; (2) startup/pre-market: elaboração do modelo de negócio, obtenção de recursos, definição da cadeia de fornecimento, desenvolvimento e validação; (3) scaleup/market: atuação ativa no mercado, 
gestão operacional integral, comercialização, expansão e rentabilização.

0 termo startup é usado comumente como sinônimo de empresa inovadora, mas é importante contextualizar que ele se origina do estágio central e mais conhecido dentro de uma estrutura maior, conforme mostrado no quadro 3.

\begin{tabular}{|l|l|l|l|}
\cline { 2 - 4 } \multicolumn{1}{c|}{} & \multicolumn{1}{c|}{ Standup / Desk } & \multicolumn{1}{c|}{ Startup / Pre-market } & \multicolumn{1}{c|}{ Scaleup /Market } \\
\hline Elemento Central & Indivíduo & Empresa & Mercado \\
\hline Foco da Ação & Visão Empreendedora & Acesso a Recursos & Obtenção de Receita \\
\hline Objetivo Estratégico & Formar Equipe & Integrar ao Ecossistema & Gerar Valor \\
\hline
\end{tabular}

Quadro 3 - Estrutura das fases empreendedoras (Fonte: adaptado de Autio et al., 2018 e Elia et al., 2020)

As aceleradoras podem iniciar sua participação em qualquer desses estágios conforme seus próprios critérios de seleção das startups, assim como também o empreendedor pode aderir ao programa em qualquer tempo, na medida que julgue necessário acessar recursos financeiros ou mentoria. Cada um desses estágios, ou fases, será analisado a seguir.

\subsection{Fase standup - visão do empreendedor}

A fase inicial, de standup, é centrada na figura do empreendedor e preocupa-se com expandir e validar a concepção da ideia. Envolve modelar a oportunidade de mercado a ser explorada e a entender quais especialistas são necessários para validar e desenvolver o conceito. Em termos estratégicos, concentra-se em montar uma equipe capaz de transformar a visão abstrata, imaginativa do empreendedor, em algo concreto, tangível, e se possível, em um produto minimamente viável ou $M V P-M i$ nimum Viable Product (Lenarduzzi \& Taibi, 2016).

Em tempo de ideação, buscar conhecimento e aprendizado voltado ao futuro faz mais sentido para inovar disruptivamente, na lógica de exploration o olhar panorâmico é mais importante, indicando caminhos e tendências possíveis. Ao buscar um nicho em um mercado existente ou inovações incrementais, na lógica de exploitation a profundidade e o conhecimento especialista capacitam a uma maior eficiência (Gupta et al., 2006). Saber qual é o aprendizado necessário para transformar a ideia em negócio qualificará melhor a mentoria.

Prever o sucesso ao empreender é um exercício limitado por várias razões (Sarasvathy, 2001). Calcular o retorno sobre uma inovação, na melhor hipótese, é apenas uma estimativa incerta; analisar competidores em um mercado inexistente baseia-se em premissas pouco realistas; reunir todas as competências necessárias com poucos recursos se torna demorado; antecipar riscos e incertezas exige um modelo de negócios validado e estruturado. Em contraste, a partir dos princípios de effectuation propostos por Sarasvathy, é possível utilizar uma lógica alternativa orientada pelos seguintes princípios: definir um limite de perdas aceitável, estabelecer alianças estratégicas com outros participantes do mercado, concentrar-se nas competências principais e mais essenciais, reagir o mais rapidamente possível às situações imprevistas.

Sarasvathy propõe três perguntas para o empreendedor: (1) Quem eu sou? (2) 0 que eu conheço? (3) Quem eu conheço? (Sarasvathy \& Dew, 2005). Essas respostas, entendidas como os meios disponíveis, são o ponto de partida para que seja estabelecida a visão do empreendedor, e até que se esgotem, o ciclo de questionamento permanece em aberto, valorizando mais o processo estratégico criativo do que o alocativo (Vanberg \& Buchanan, 1991). Falhar é considerado uma contingência necessária e a gestão de risco baseia-se em definir limites aceitáveis, falhando rápido e falhando barato. A geração de valor resulta de um menor custo agregado por ideia levada ao mercado, potencializada na criação e exploração de novos mercados antes da concorrência.

A capacidade empreendedora e o desenvolvimento da ideia são aspectos que a aceleradora precisa lidar de forma separada. Ao processo seletivo, cabe garantir que haja uma capacidade empreendedora na startup suficiente para enfrentar as incertezas efectuais e os riscos causais inerentes ao processo de inovação. À mentoria, cabe garantir que a ideia possa ser desenvolvida ou até mesmo totalmente remodelada. Um processo de seleção fraco sobrecarregará a mentoria, principalmente na abordagem efectual, na qual as dificuldades tendem a ser maiores do que na causal.

- Proposição 1: Aceleradoras que selecionam empreendedores orientados à lógica efectual (causal) associam-se a ideias de negócio com maior probabilidade (menor probabilidade) de retirar valor do processo de mentoria, obtendo tração na fase de startup. 
Um dos principais motivadores para que um empreendedor participe de um programa de aceleração é o acesso a recursos financeiros. No entanto, ao prevalecer uma lógica causal, direcionada à busca de objetivos pré-definidos e retornos já calculados e esperados a partir de um plano de negócios formalizado, o aporte de mentoria e acesso à rede de parceiros por meio da aceleradora torna-se pouco efetivo, agregando pouco valor ao empreendedor, visto que a execução da ideia passa a estar orientada à gestão (risco) e não à inovação (incerteza). Nesse cenário, quando apenas a execução de uma ideia pré-definida está em jogo, a obtenção de um financiamento bancário seria suficiente, sem expor o empreendedor a ceder parte da sua participação e às interferências na operação decorrentes de um programa de aceleração.

Assim, a Proposição 1 busca traduzir um dos dilemas das aceleradoras, que é decidir entre investir cedo em uma visão empreendedora a ser tangibilizada (incerteza efectual) ou investir tarde em um modelo de negócio definido a ser operado (risco causal), sugerindo que as aceleradoras devem preferir se concentrar em buscar empreendedores com uma visão em construção sobre uma lógica efectual, em preço e timing adequados para capturar um valor maior sobre o potencial da ideia do empreendedor.

\subsection{Fase startup - acesso a recursos}

A fase intermediária, de startup, desloca-se da figura do empreendedor para a empresa em si mesma. Assegurando que a entrega final da fase anterior tenha sido os elementos que definem a primeira versão do modelo de negócios, que representa a tangibilização da visão do empreendedor traduzida pela sua equipe de trabalho e mentoria de aceleração. A partir desse ponto, o foco estratégico direciona-se para a obtenção de recursos materiais e imateriais que permitam validar o modelo de negócios como uma versão final e escalável para o crescimento.

0 empreendedor com um modelo de negócio a ser validado precisa ampliar seu acesso a recursos, sendo importante destacar o termo "acesso a recursos", e não "posse de recursos": acesso traz a ideia de que um recurso pode ser utilizado em parceria, de uma forma colaborativa e flexível com o detentor dele, enquanto posse traz a ideia de que um recurso precisa ser obtido e mantido exclusivamente de uma forma competitiva. A lógica efectual baseia-se na construção de redes colaborativas, sendo um fenômeno direcionado a redes e dependente de redes (Kerr \& Coviello, 2020).

Dois tipos de recurso são necessários ao empreendedor: financeiros e não financeiros. 0 valor de uma aceleradora está na sua capacidade de prover acesso a ambos. Os recursos financeiros normalmente são próprios e iniciais, objetivando suportar os estágios necessários para que se valide o mercado. Se for necessário um aporte maior para ganhos de escala mais robustos, ou acesso a tecnologias mais caras, é provável que se busque o envolvimento de outros investidores que complementem os valores necessários. Os recursos não financeiros podem ser bastante variados: localizar um especialista específico, entender uma regulação, acessar um recurso tecnológico, suporte jurídico ou administrativo, uma campanha de marketing, formação educacional e similares. Seja qual for a demanda, ela tende a ser resolvida a partir do acesso a uma rede de participantes que possa se envolver com a visão do empreendedor, fornecendo o acesso aos recursos necessários, superando quaisquer barreiras e restrições (Kerr \& Coviello, 2020).

Enquanto na fase anterior (standup), as decisões eram mais internas, no âmbito restrito do empreendedor e aceleradora. Nessa fase lida-se mais com questões externas envolvendo parcerias e mercado. As relações humanas se tornam determinantes para validar e operar o modelo de negócio, ampliando sua capacidade de ser escalado. A comunidade formada ao redor desse objetivo precisa dispor de processos e artefatos que conectem a prática da mentoria ao mercado. Essa conexão exige uma identidade de grupo que empodere seus participantes com união, abertura a novas perspectivas e ação efetiva, num espaço coordenado de transparência e diálogo (Theodorakopoulos et al., 2014).

Buscar alianças estratégicas é uma opção efectual, enquanto analisar competidores é uma opção causal, como traduzido por Sarasvathy $(2001 ; 2009)$ pelo princípio denominado "Crazy Quilt", orientado a estabelecer a relação estratégica com outros participantes do mercado, e pela definição dos meios na pergunta "Quem eu conheço?". Nesse contexto, o acesso a informações do ecossistema ou de mercado que permitam suportar essas opções é uma capacidade essencial para as aceleradoras.

Os tipos de alianças a serem desenvolvidas dentro de uma visão de portfólio podem se orientar pelo objetivo de diferenciação e, assim, privilegiar alianças do tipo exploration voltadas à experimentação, descoberta e inovação; ou, por outro lado, se orientar pelo objetivo de custo, privilegiando alian- 
ças exploitation voltadas à operação, refinamento e processos (Yamakawa, Zhiang \& Lin, 2011). 0 equilíbrio desse portfólio de alianças entre tecnológica e eficiência é um aspecto para o qual a aceleradora também precisa prestar atenção.

Aceleradoras precisam estar atentas à gestão da rede de relacionamentos criada a partir do seu programa de aceleração, garantindo a lógica adequada, seja causal ou efectual, conforme o risco ou incerteza associado ao problema, além de manter uma mediação e governança adequada para aproximar ou afastar participantes, redefinir ou interromper laços, buscando interações cooperativas e baseadas em confiança (Kerr \& Coviello, 2020).

- Proposição 2: Aceleradoras que são capazes de estabelecer e mediar redes de relacionamento com maior grau (menor grau) de confiança e cooperação entre seus participantes chegam mais rapidamente (menos rapidamente) na fase de scaleup.

Um dos principais motivadores para que um empreendedor participe de um programa de aceleração é justamente acelerar seu processo de startup. Se o valor da rede acessada por intermédio do programa não for equilibrado, é provável que os processos não tenham um fluxo adequado. Uma rede para essa finalidade possui várias dimensões e dualidades; os laços fortes reforçam a ação; os laços fracos reforçam a criação; os mecanismos sociais aproximam os participantes éticos e afastam os oportunistas; a governança administra os contratos, sejam informais ou formais, garantindo confiança e cooperação; o tamanho e centralidade da rede provê acesso aos recursos necessários.

Assim, a Proposição 2 busca traduzir a assertividade esperada do programa de aceleração, operacionalizada por meio de uma rede confiável e cooperativa, sugerindo que as aceleradoras devem preferir se concentrar na construção e manutenção de uma rede com essas características como sua principal proposta de valor e ativo estratégico.

\subsection{Fase scaleup - obtenção de receita}

A fase final, de scaleup, desloca-se da figura da empresa para o mercado, considerando que a entrega da fase anterior é um modelo de negócio validado e pronto para ser escalado. A partir desse ponto, o foco estratégico direciona-se para a obtenção de receita, permitindo um retorno financeiro e gratificação pessoal que venha a recompensar os participantes por todo o esforço realizado desde o primeiro rascunho numa folha em branco até a chegada ao mercado com uma inovação.

Uma implicação importante que precisa ser considerada ao se evoluir para a fase de scaleup é a natureza causal mais forte que tende a ser assumida pela aceleradora em sua mentoria, visando o encerramento do programa de aceleração e a perspectiva iminente de desinvestimento. A maturação da aspiração inicial do empreendedor naturalmente tende a evoluir de uma lógica efectual para uma lógica causal (Sarasvathy \& Dew, 2005), o que modela os programas de aceleração para estimular o uso de objetivos estáticos, indicadores de performance e processos operacionais nessa fase final, empurrando a startup na direção de uma miniempresa com foco operacional. 0 primeiro contato com o mercado tende a apresentar uma incerteza e uma complexidade que provavelmente se beneficiaria mais da lógica efectual do que da lógica causal. 0 desafio aqui é equilibrar as duas lógicas, mantendo o viés empreendedor, mesmo nessa fase final.

É provável que a incerteza ao longo das fases descritas mude sua característica sem desaparecer por completo. Não perceber essa mudança pode induzir ao entendimento de que ela foi superada, quando na verdade apenas mudou sua natureza. Ao manifestar-se de diferentes formas (Milliken, 1987): relacionada aos movimentos de mercado e novas tecnologias (state uncertainty), pelo desconhecimento ou falta de informação que resulte numa incapacidade de previsão (effect uncertainty), ou pela dificuldade em avaliar todas as consequências de uma decisão complexa (response uncertainty); a incerteza exige da startup a manutenção da capacidade de lidar com ela, situação para a qual a lógica efectual pode ser considerada.

Uma forma de interpretar o programa de aceleração, do ponto de vista da aceleradora profissional, é percebê-lo como comprador de lógica efectual na fase standup (alto valor aspiracional para a construção de uma inovação disruptiva) e vendedor de lógica causal na fase scaleup (alto valor operacional para a obtenção de receita). A maior característica dos programas de aceleração é formar e orientar o empreendedor a partir de mentorias, metodologias e ferramentas que refletem uma lógica causal, determinística, baseada em retorno sobre o investimento e gestão de riscos, elementos diferentes da lógica efectual, baseada em retorno sobre a inovação, contingenciamento de incertezas e uma 
postura aberta e criativa.

Na fase de seleção, que abre um programa de aceleração, são escolhidas várias startups conforme critérios da aceleradora (Pauwels et al.,2016), abrindo um portfólio de investimentos. Na largada, é impossível saber quais negócios apresentarão maior crescimento e sucesso. 0 risco da aceleradora com cada um dos investimentos torna-se mais visível nessa fase, implicando em decisões que podem promover ou rebaixar a categoria das startups participantes do programa e, numa situação mais crítica, definir a sua inviabilidade com ganhos inferiores ao investido ou mesmo perda total. A gestão desse portfólio de sucessos e fracassos pode ampliar a tensão entre aceleradora e empreendedor.

Considerando que o desinvestimento da aceleradora após o encerramento do programa pode ser realizado de forma parcial, mantendo uma participação futura, questiona-se que não abandonar a lógica efectual, mesmo numa fase operacional, faça sentido e possa contribuir para outros desafios até que a empresa se torne operacionalmente madura. Dificilmente o nível de incerteza será reduzido de forma segura em uma primeira tentativa de ida ao mercado.

0 dinamismo do mercado explorado pela startup é um aspecto moderador do equilíbrio entre as lógicas. Campos altamente inovadores e mercados exponenciais tendem a exigir um aprendizado maior na lógica exploration, acompanhando a tomada de decisão efectual; campos maduros e menos orientados à tecnologia se valem mais da lógica exploitation, acompanhando a lógica causal (Uotila et al., 2009). As características do mercado e da tecnologia podem ajudar aceleradora e empreendedor a buscar um ponto ideal de equilíbrio.

A intersecção de effectuation com o campo da economia tem buscado ampliar a compreensão dos efeitos relacionados à economia empreendedora. A partir de amostras empíricas, evidencia-se que investidores efectuais tendem a falhar menos e a obter maior valor, mesmo com volumes financeiros menores do que investidores causais (Wiltbank, Read, Dew \& Sarasvathy, 2009; Weigand, 2019). Uma das conclusões é de que investidores efectuais buscam investir em áreas que possuem maior domínio, com uma atitude de alto engajamento e suporte direto à startup (smart money), em linha com a evolução e dinâmica das tendências tecnológicas. Investidores causais preferem mercados mais estáveis, maior previsibilidade com menor risco e menor retorno, investindo maiores volumes financeiros.

Investidores anjo (business angels) que buscam retorno financeiro como principal objetivo, ao avaliarem subjetivamente o potencial de uma ideia empreendedora, tendem a valorizar a lógica efectual do empreendedor ao estimarem performance futura (Schmidt, Bendig \& Brettel, 2018).

- Proposição 3: Aceleradoras que finalizam o programa de aceleração com startups operadas pela lógica efectual (causal) obtém retornos superiores (inferiores) na sua venda de participação para investidores de risco.

A velocidade com que os empreendedores e as aceleradoras objetivam acessar o mercado a partir da ideação tem sido medida em semanas ou meses, num prazo estabelecido pela régua da duração dos programas de aceleração. Essa janela de tempo precisa ser coerente e suficiente para uma empresa se capacitar a lidar com as incertezas do mercado. Nesse contexto, mesmo que bem-sucedidos em um primeiro momento, o empreendedor e a startup ainda são uma ideia, possuem recursos escassos, dependem de uma rede de apoio e, mesmo tendo transitado pelas fases descritas, não atingiram a musculatura necessária para se comparar às empresas já estabelecidas. Ao atingir um patamar de desempenho menos dependente dos investidores de risco, o que pode demorar vários anos, então é provável que uma mudança orgânica para a lógica causal seja mais adequada (Picken, 2017).

Assim, a Proposição 3 busca traduzir que a ida ao mercado após o processo de aceleração não encerra o ciclo de desenvolvimento de um negócio, para uma startup continua sendo um desafio empreender. Mesmo que nessa fase ela se pareça com uma miniempresa já estruturada em processos, $o$ tempo decorrido é curto para que ela possa ser considerada madura.

\section{Considerações Finais}

Empreender tem sido a escolha profissional de um número crescente de pessoas. Sejam elas motivadas por necessidade em função de contexto econômico, ou por oportunidade ao vislumbrar uma inovação promissora, há em comum o desejo de prosperar, ajudar a sociedade, deixar uma marca pessoal, um legado. Ecossistemas dedicados a apoiar empreendedores iniciantes ou experientes se desenvolveram em todas as principais cidades do planeta e há um incentivo social reforçado pela valorização do sucesso das inúmeras startups já consolidadas. 
A partir do acesso facilitado à tecnologia, dinheiro e conhecimento, com o apoio de inúmeros agentes de fomento e incentivo ao empreendedorismo e à inovação, diversos empreendedores procuram suporte especializado nas aceleradoras profissionais para sua jornada empreendedora. Esse fenômeno tem se tornado comum em diversos países, chamando a atenção de pesquisadores interessados em compreendê-lo com mais profundidade.

A partir do suporte fornecido pela teoria de Causation - Effectuation (Sarasvathy, 2001; 2009) para a tomada de decisão empreendedora, buscou-se, neste ensaio teórico, avaliar o relacionamento entre as aceleradoras e as startups participantes dos programas de aceleração oferecidos aos empreendedores (Pauwels et al., 2016). A partir da identificação de três fases bem definidas, refletiu-se sobre as escolhas estratégicas mais adequadas para maximizar a geração de valor em cada momento (Autio et al, 2018 e Elia et al., 2020).

Considerando os diferentes objetivos dos participantes envolvidos e as tensões que são naturais em processos colaborativos, buscou-se a construção de um framework capaz de assinalar pontos de atenção importantes que possam contribuir para reduzir riscos, incertezas e aumentar a chance de sucesso.

Como conclusão do ensaio teórico, o quadro 4 agrupa e apresenta para cada fase: os objetivos estratégicos de cada parte, os alinhamentos esperados e os conflitos potenciais na relação entre empreendedor e aceleradora, assim como as proposições que sugerem a maximização da geração de valor para empreendedores e aceleradoras.

\begin{tabular}{|c|c|c|c|}
\hline & Standup / Desk & Startup / Pre-market & Scaleup / Market \\
\hline Elemento Central & Indivíduo & Empresa & Mercado \\
\hline $\begin{array}{l}\text { Objetivo Empreende- } \\
\text { dor }\end{array}$ & $\begin{array}{l}\text { Transformar a ideia de negó- } \\
\text { cio em um protótipo. }\end{array}$ & $\begin{array}{l}\text { Transformar o protótipo em } \\
\text { um modelo de negócio esca- } \\
\text { lável. }\end{array}$ & $\begin{array}{l}\text { Transformar o modelo de } \\
\text { negócio em receita exponen- } \\
\text { cial. }\end{array}$ \\
\hline Objetivo Aceleradora & $\begin{array}{l}\text { Selecionar ideias inovadoras } \\
\text { com potencial exponencial. }\end{array}$ & $\begin{array}{l}\text { Fornecer mentoria, metodo- } \\
\text { logia, educação e rede de } \\
\text { relacionamento. }\end{array}$ & $\begin{array}{l}\text { Desinvestir com o máximo de } \\
\text { retorno financeiro. }\end{array}$ \\
\hline Alinhamento Esperado & $\begin{array}{l}\text { Formatar a ideia em uma } \\
\text { proposta de modelo de negó- } \\
\text { cio. }\end{array}$ & $\begin{array}{l}\text { Acelerar o processo de ida ao } \\
\text { mercado. }\end{array}$ & $\begin{array}{l}\text { Gerar receita e valorização de } \\
\text { mercado. }\end{array}$ \\
\hline Conf & $\begin{array}{l}\text { Simplificação das incertezas } \\
\text { inerentes ao processo inova- } \\
\text { dor. }\end{array}$ & $\begin{array}{l}\text { Competição pelo acesso aos } \\
\text { recursos entre as startups } \\
\text { aceleradas. }\end{array}$ & $\begin{array}{l}\text { Abandono da lógica efectual e } \\
\text { reforço excessivo da lógica } \\
\text { causal. }\end{array}$ \\
\hline Proposição & $\begin{array}{l}\text { Aceleradoras que selecionam } \\
\text { empreendedores orientados } \\
\text { à lógica efectual (causal) } \\
\text { associam-se a ideias de negó- } \\
\text { cio com maior probabilidade } \\
\text { (menor probabilidade) de } \\
\text { retirar valor do processo de } \\
\text { mentoria obtendo tração na } \\
\text { fase de startup. }\end{array}$ & $\begin{array}{l}\text { Aceleradoras que são capazes } \\
\text { de estabelecer e mediar re- } \\
\text { des de relacionamento com } \\
\text { maior grau (menor grau) de } \\
\text { confiança e cooperação para } \\
\text { as startups chegam mais } \\
\text { rapidamente (menos rapi- } \\
\text { damente) na fase de scaleup. }\end{array}$ & $\begin{array}{l}\text { Aceleradoras que finalizam o } \\
\text { programa de aceleração com } \\
\text { startups operadas pela lógica } \\
\text { efectual (causal) obtêm re- } \\
\text { tornos superiores (inferio- } \\
\text { res) na sua venda de partici- } \\
\text { pação para investidores de } \\
\text { risco. }\end{array}$ \\
\hline
\end{tabular}

Quadro 4 - Framework Estratégico (Fonte: elaborado pelo autor)

Empreendedores, usualmente com tendência efectual, e aceleradoras, usualmente com tendência causal, devem buscar um ponto de intersecção construtivo na medida em que forem capazes de equilibrar seus diferentes interesses em cada um dos diversos contextos enfrentados nos estágios de evolução, coordenando estratégias específicas para atingir o melhor resultado conjunto. É esperado que ganhos maiores em dinheiro, tempo e qualidade, possam ser atingidos para ambos na medida em que as três proposições analisadas e o conjunto do framework sejam incorporados aos processos conduzidos durante o programa de aceleração.

A aceleradora, mais que a startup, tende a cumprir um papel de apontar e regular o equilíbrio entre as várias dualidades presentes na atividade empreendedora, seja do ponto de vista do aprendizado associado à exploitation - exploration (March, 1982; 1991) ou da tomada de decisão associada à causation - effectuation (Sarasvathy, 2001; 2009). No entanto, precisa, em cada fase, estar disposta a operar mais em um modo do que no outro a fim de potencializar o valor que pode ser extraído, da ideia, do modelo de negócio e do mercado, valorizando assim, sua mentoria e possibilitando ao empreendedor uma jornada mais rápida com menos dificuldades ao longo do desenvolvimento, além de crescimento do seu negócio. 
As abordagens causal ou efectual são complementares, não sendo possível afirmar que uma é superior à outra, pois ambas são habilitadoras do empreendedorismo e da inovação. 0 sucesso parece estar associado à sabedoria de aplicar a lógica mais adequada ao momento ou ao problema em questão, e que esteja reforçada pelo vínculo a uma rede de colaboração eficiente e eficaz. Nesses aspectos, a relação empreendedor - aceleradora está longe de ser pacífica e constitui um desafio comum a ser superado, que se soma ao já difícil desafio de empreender.

\subsection{Contribuições}

Aceleradoras profissionais são um agente recente, importante para o desenvolvimento do ecossistema de inovação e para o estímulo ao empreendedorismo, e se apresentam como um campo relevante pouco explorado na pesquisa, contrastando com a elevada produção científica voltada ao empreendedor.

Este ensaio teórico busca contribuir com uma visão gerencial sobre o processo de aceleração de startups, analisando a relação empreendedor - aceleradora e propondo um framework para guiar os gestores dos programas de aceleração e os empreendedores à frente de startups iniciantes. No âmbito acadêmico, busca ampliar a discussão teórica sobre a geração de valor das aceleradoras profissionais no contexto do empreendedorismo.

\subsection{Recomendações futuras}

O modelo teórico utilizado para o empreendedor e a aceleradora neste artigo é conceitual. Recomenda-se que estudos futuros aprofundem como os diferentes perfis de empreendedor e os variados modelos de aceleradora se diferenciam para maximizar os resultados da inovação. Também é importante que trabalhos futuros se dediquem a validar empiricamente o framework aqui proposto por meio de pesquisas em ambientes reais de aceleradoras para aceitar ou rejeitar as proposições realizadas. Esforços dessa natureza retornam para a sociedade na forma de maior compreensão e estímulo ao empreendedorismo, refletindo em benefícios e prosperidade social ao estimular o crescimento de novos negócios.

\section{Notas}

${ }^{1}$ Disponível em https://www.cbinsights.com/research-unicorn-companies, recuperado em 04 de janeiro de 2021.

\section{Referências}

Autio, E., Nambisan, S., Thomas, L. D., \& Wright, M. (2018). Digital affordances, spatial affordances, and the genesis of entrepreneurial ecosystems. Strategic Entrepreneurship Journal, 12(1), 72-95.

Brown, T. (2008). Design thinking. Harvard business review, 86(6), 84.

Chandler, G. N., DeTienne, D. R., McKelvie, A., \& Mumford, T. V. (2011). Causation and effectuation processes: A validation study. Journal of business venturing, 26(3), 375-390.

Cohen, S., \& Hochberg, Y. V. (2014). Accelerating startups: The seed accelerator phenomenon.

da Silva, J. A. B., \& Silva, M. S. V. (2019). Análise da evolução do empreendedorismo no Brasil no período de 2002 a 2016. Revista Estudos e Pesquisas em Administração, 3(2), 115-137.

Elia, G., Margherita, A., \& Passiante, G. (2020). Digital entrepreneurship ecosystem: How digital technologies and collective intelligence are reshaping the entrepreneurial process. Technological Forecasting and Social Change, 150, 119791.

Gupta, A. K., Smith, K. G., \& Shalley, C. E. (2006). The interplay between exploration and exploitation. Academy of management journal, 49(4), 693-706.

Jeong, J., Kim, J., Son, H., \& Nam, D. I. (2020). The Role of Venture Capital Investment in Startups' Sustainable Growth and Performance: Focusing on Absorptive Capacity and Venture Capitalists' Reputation. Sustainability, 12(8), 3447.

Jiang, Y., \& Rüling, C. C. (2019). Opening the black box of effectuation processes: Characteristics and dominant types. Entrepreneurship Theory and Practice, 43(1), 171-202.

Jiang, Y., \& Tornikoski, E. T. (2019). Perceived uncertainty and behavioral logic: Temporality and unanticipated consequences in the new venture creation process. Journal of Business Venturing, 34(1), 2340.

Kerr, J., \& Coviello, N. (2020). Weaving network theory into effectuation: A multi-level reconceptualiza- 
tion of effectual dynamics. Journal of Business Venturing, 35(2), 105937.

Lee, A. (2013). Welcome to the unicorn club: Learning from billion-dollar startups. Cowboy Ventures (blog).

Lenarduzzi, V., \& Taibi, D. (2016, August). Mvp explained: A systematic mapping study on the definitions of minimal viable product. In 2016 42th Euromicro Conference on Software Engineering and Advanced Applications (SEAA) (pp. 112-119). IEEE.

March, J. G. (1982). Theories of choice and making decisions. Society, 20(1), 29-39.

March, J. G. (1991). Exploration and exploitation in organizational learning. Organization science, 2(1), 71-87.

McKelvie, A., Chandler, G. N., DeTienne, D. R., \& Johansson, A. (2019). The measurement of effectuation: highlighting research tensions and opportunities for the future. Small Business Economics, 1-32.

Milliken, F. J. (1987). Three types of perceived uncertainty about the environment: State, effect, and response uncertainty. Academy of Management review, 12(1), 133-143.

Mintzberg, H. (1994). The rise and fall of strategic management. Harvard Business Review, 1(02).

Osterwalder, A., \& Pigneur, Y. (2010). Business model generation: a handbook for visionaries, game changers, and challengers. John Wiley \& Sons.

Pauwels, C., Clarysse, B., Wright, M., \& Van Hove, J. (2016). Understanding a new generation incubation model: The accelerator. Technovation, 50, 13-24.

Picken, J. C. (2017). From founder to CEO: An entrepreneur's roadmap. Business Horizons, 60(1), 7-14.

Ries, E. (2012). A startup enxuta. Leya.

Sarasvathy, S. D. (2001). Causation and effectuation: Toward a theoretical shift from economic inevitability to entrepreneurial contingency. Academy of management Review, 26(2), 243-263.

Sarasvathy, S. D. (2009). Effectuation: Elements of entrepreneurial expertise. Edward Elgar Publishing.

Sarasvathy, S. D., \& Dew, N. (2005). Entrepreneurial logics for a technology of foolishness. Scandinavian journal of Management, 21(4), 385-406.

Schmidt, S., Bendig, D., \& Brettel, M. (2018). Building an equity story: the impact of effectuation on business angel investments. Journal of Business Economics, 88(3-4), 471-501.

Theodorakopoulos, N., Kakabadse, N. K., \& McGowan, C. (2014). What matters in business incubation? A literature review and a suggestion for situated theorising. Journal of small business and enterprise development.

Uotila, J., Maula, M., Keil, T., \& Zahra, S. A. (2009). Exploration, exploitation, and financial performance: analysis of S\&P 500 corporations. Strategic Management Journal, 30(2), 221-231.

Van Astyne, M. W., Parker, G. G., \& Choudary, S. P. (2016). Pipelines, platforms, and the new rules of strategy. Harvard business review, 94(4), 16.

Vanberg, V. J., \& Buchanan, J. M. (1991). The Market as a Creative Process. Economics and Philosophy, 7, 167-186.

Vanderstraeten, J., \& Matthyssens, P. (2012). Service-based differentiation strategies for business incubators: Exploring external and internal alignment. Technovation, 32(12), 656-670.

Weiblen, T., \& Chesbrough, H. W. (2015). Engaging with startups to enhance corporate innovation. California management review, 57(2), 66-90.

Weick, K. E. (1979), The social psychology of organizing. M@ n@ gement, 18(2), 189-193.

Weigand, C. (2019). Beyond the finance paradigm: the entrepreneurial logic of financial resource acquisition from an effectuation perspective. International Journal of Entrepreneurial Venturing, 11(5), 440-460.

Wiltbank, R., Read, S., Dew, N., \& Sarasvathy, S. D. (2009). Prediction and control under uncertainty: Outcomes in angel investing. Journal of Business Venturing, 24(2), 116-133.

Yamakawa, Y., Yang, H., \& Lin, Z. J. (2011). Exploration versus exploitation in alliance portfolio: Performance implications of organizational, strategic, and environmental fit. Research Policy, 40(2), 287296.

Zimmerer, T. W., Scarborough, N. M., \& Wilson, D. (2008). Entrepreneurship and small business management. Jakarta: Salemba Empat. Pg, 57. 